\title{
Survey of food handlers in bukas (a type of local restaurant) in Lagos, Nigeria about typhoid fever
}

\author{
Stella I. Smith ${ }^{1 *}$, Chimere O. Agomo ${ }^{2}$, Moses Bamidele ${ }^{1}$, Bolanle O. Opere ${ }^{3}$, Olusimbo 0. \\ Aboaba $^{4}$ \\ ${ }^{1}$ Molecular Biology and Biotechnology Division, Nigerian Institute of Medical Research, Lagos, Nigeria; ${ }^{*}$ Corresponding Author: \\ stellaismith@yahoo.com \\ ${ }^{2}$ Biochemistry and Nutrition Division, Nigerian Institute of Medical Research, Lagos, Nigeria \\ ${ }^{3}$ Department of Microbiology, Lagos State University, Lagos, Nigeria \\ ${ }^{4}$ Department of Microbiology, University of Lagos, Lagos, Nigeria
}

Received 30 March 2010; revised 26 April 2010; accepted 27 April 2010.

\begin{abstract}
Purpose: The study was conducted to survey the knowledge and behavioural practices of food handlers in bukas (a type of local restaurant) in Nigeria with the aim of assessing the hygiene practices of food handlers and whether they were knowledgeable about typhoid fever and its mode of transmission. Methods: One hundred and seventy four (174) Respondents were administered questionnaires on their sociodemographic characteristics, behavioural practices and knowledge of typhoid fever. Results: Majority of the food handlers drank pure water $(32.1 \%)$, borehole water $(32.6 \%)$ and public tap water $(31.1 \%)$ at the about the same frequecy. More than half $(62.2 \%)$ washed their hands with water only before eating while $27.7 \%$ did not wash their hands always before preparing food. After using toilets, $71.9 \%$ washed their hands with soap and water while $28.1 \%$ washed their hands with only water. When asked if they had heard about typhoid fever $90 \%$ said they had heard, out of which $15.6 \%$ did not know how it was contracted while the others had partial knowledge. Conclusion: Food handlers play a prominent role in the transmission of typhoid fever and so it is important that the food handlers are well informed about their hygiene status and the causes of typhoid fever transmission and ways by which typhoid fever spread is prevented. This will go a long way to help reduce the incidence of typhoid fever in the country.
\end{abstract}

Keywords: C Food Handlers; Salmonella; Typhoid Fever; Buka

\section{INTRODUCTION}

Salmonella enterica serovar Typhi is the causative agent of typhoid fever and the route of transmission is faecal-oral. There are certain areas where the infection is most common such as areas where the sanitary conditions are unhygienic and there is lack or poor supply of water. Polluted water is the most common source of typhoid. Other sources occur with infected vegetables fertilized by night soil, shell fish taken from sewage contaminated beds, and eating of raw contaminated milk and milk products [1].

The symptoms of typhoid fever include a sudden onset of sustained fever, severe headache, nausea and severe loss of appetite. An estimated 700,000 deaths occur from an annual incidence of approximately 21 million cases [1].

In developed countries where there are adequate sanitary facilities, only sporadic cases from typhoid fever occur at fairly constant levels with very few cases coming from countries endemic with typhoid fever. The reverse is the case for developing countries where there are no proper sanitary facilites. A study by Todd et al. [2-4] revealed that the food workers tested were either asymptomatic or were at the stage before infection shows symptons and so were not conscious of their infections. The report strongly suggested the hands of the food handlers as the most likely route through which the pathogen could be transmitted. The implicated pathogens were norovirus, hepatitis A virus, Salmonella, Shigella and Staphylococcus aureus. Experiments conducted by the authors on pathogen survival indicated that transmission depends on species, delivery route of the inoculum, the temperature and period of pathogen exposure, contact surface type, and relative humidity.

Other common food worker associated pathogens are stapylococci or streptrococci from skin and nasopharyngeal or oropharyngeal infections. This gave a strong 
backing on the importance of effective hand hygiene and the use of barriers throughout the work shift.

In another study from Ethiopia by Andargie et al. [5] on the prevalence of bacteria and intestinal parasites among food handlers, Salmonella species was not isolated from the food handlers. However other pathogens were implicated in the stool and finger nail content of the food handlers and their findings further stressed on the importance of food handlers as potential sources of infections.

A study by Malhotra et al. [6] on changes in knowledge, attitudes and self-reported hand washing practises among food handlers three months after providing them health education showed the importance of health education in food and personal hygiene. The authors suggested including health education in the existing guidelines for food establishment in Delhi and other places.

The personal and food hygiene practices in South African delicatessen sections of retail outlets were examined using structured questionnaires [7]. The authors concluded on the need for proper and continuous training in personal and general hygiene not only for food handlers but also for management.

Another study in Nigeria by Okojie et al. [8] using structured questionnaires to assess food handlers in a Nigerian University, corroborated the view of vanToder et al. [7].

Recently, Smith et al. [9-10], reported on the prevalence of $S$. enterica serovar Typhi amongst food handlers. S. enterica serovar Typhi accounted for 5.7\% of the total microorganisms isolated from the food handlers and $40 \%$ of Salmonella spp. Food handlers are located in various areas in Lagos metropolis, a city in Nigeria and depending on the cost of food, the food sold to those of the lower class are usually very cheap and sometimes not prepared in hygienic conditions. In addition, the environment could be close to a very dirty gutter and with so much litter around and flies.

This study was conducted to assess the knowledge about typhoid fever and hygiene practises of food handlers in buka (a type of local restaurant) in Lagos.

\section{METHODS}

One hundred and seventy four (174) questionnaires were taken based in a previous survey aiming to determine the prevalence of $S$. enterica serovar Typhi amongst clinical samples [11].

The study is a cross-sectional descriptive one consisting of 174 "asymptomatic" food handlers in bukas. It was carried out in Lagos, a city in Nigeria between June 2006 and March 2007. The respondents were sampled by convenient sampling and interviewed using semi structured questionnaires for data collection. A total of 230 food handlers were asked to participate in the study and 56 (24\%) declined to participate. The semi-structured questionnaire was administered and filled by a member of the research team. There were 25 questions in all and none was leading in nature and the questionnaire was administered in English and where the food handlers were not well educated to understand the language, pidgin English a language common amongst majority of Nigerians was used. Verbal consent was obtained from the food handlers before the questionnaire was administered. An average of four people worked in the bukas selected and it was noted that for bigger bukas of about 50 food handlers, there was no cooperation amongst the food handlers. The reason why the selection made was with smaller bukas. However there was cooperation in one local government were the food handlers were gathered in groups (of 8) for questionnaires to be administered. Eleven markets were visited in all. All the respondents interviewed cooked food on site and they are usually on ground very early to prepare food.

The questionnaire had a brief introduction about typhoid fever, the Respondent's background, behavioural practices and buka.

Other questions included whether there was a toilet facility and how it was used. The last part of the questionnaire included Respondent's knowledge of how typhoid fever was contracted and if there was prior knowledge of the disease or diagnosis and treatment given.

Method of data analysis: The date was analysed using Epi info 6.0.

\section{RESULTS}

\subsection{Sociodemographic Characteristics}

The respondents were mostly females $77.6 \%$. Their ages ranged between 15 and 62 years with a mean of $32.6 \pm$ 11.3 years while the men comprised $22.4 \%$ of the respondents with a mean of $30.1 \pm 8.3$ years. There was no significant difference $(\mathrm{P}=0.47)$ between the ages of the males and the females.

When the food handlers were assessed in terms of tribe more than half of the respondents were Yoruba by tribe $(64.9 \%)$, followed by Ibos $(21.8 \%)$. The other tribes comprise $13.3 \%$ (Table 1). Out of eleven markets visited Yaba, Oshodi and Agboju markets (40\%) were the markets where most of our Respondents were interviewed (Table 2).

\subsection{Behavioral Practices}

The major sources of drinking water were Borehole 62 
(32.6\%), packaged ("pure") water 61 (32.1\%) and public tap $59(31.1 \%)$. The Well water was not popular as a source of drinking water $6(3.2 \%)$ (Table 1). Some of the respondents used more than one water source for drinking.

For cooking and washing of plates the major sources of water were borehole $54.3 \%$, well water $24.0 \%$ and public tap $20.2 \%$.

Most of the respondents (93.5\%) ate some foods with their bare hands. The foods eaten with bare hands are the staple foods like Eba/starch (23.7\%), amala/lafu (17.7\%), Fufu (17.2\%), yam (14.4\%) and Semovita (12.0\%).

All the respondents washed their hands before eating however only $37.8 \%$ washed their hands with soap and water while $62.2 \%$ washed their hands with only water.

Table 1. Sociodemographic characteristics of food handlers in bukas in Nigeria.

\begin{tabular}{|c|c|c|}
\hline Characteristics & Frequency & $\%$ \\
\hline \multicolumn{3}{|l|}{ Age (years) } \\
\hline $15-40$ & 138 & 79.3 \\
\hline$>40$ & 36 & 20.7 \\
\hline \multicolumn{3}{|l|}{ Sex } \\
\hline Male & 39 & 22.4 \\
\hline Female & 135 & 77.6 \\
\hline \multicolumn{3}{|l|}{ Educational Status } \\
\hline No formal education & 10 & 5.7 \\
\hline Primary & 140 & 80.5 \\
\hline Post-primary & 23 & 13.2 \\
\hline Post secondary & 1 & 0.6 \\
\hline \multicolumn{3}{|l|}{ Hand-washing practice } \\
\hline \multicolumn{3}{|l|}{ after toilet } \\
\hline $\begin{array}{l}\text { Yes with soap and } \\
\text { water }\end{array}$ & 125 & 71.8 \\
\hline Yes with only water & 52 & 28.2 \\
\hline \multicolumn{3}{|c|}{ *Sources of drinking water } \\
\hline Borehole & 62 & 32.6 \\
\hline Public tap & 59 & 31.1 \\
\hline Pure water & 61 & 32.1 \\
\hline Well & 6 & 3.2 \\
\hline Others & 2 & 1.1 \\
\hline \multicolumn{3}{|l|}{ Tribe of Respondents } \\
\hline Yoruba & 113 & 64.9 \\
\hline Ibo & 38 & 21.8 \\
\hline Delta & 11 & 6.3 \\
\hline Hausa & 3 & 1.7 \\
\hline Edo & 1 & 0.6 \\
\hline Togolese & 1 & 0.6 \\
\hline Others & 7 & 4.0 \\
\hline
\end{tabular}

*The Respondents had more than one source of drinking water.
Table 2. Shows the market and the number of Respondents interviewed in each market.

\begin{tabular}{lcc}
\hline MARKET & Freq & Percent \\
\hline AGBOJU & 20 & 11.0 \\
ARAROMI & 8 & 4.0 \\
BADAGRY & 8 & 4.0 \\
IYANA IBA & 13 & 7.0 \\
KETU & 14 & 5.0 \\
MAFOLUKU & 17 & 9.0 \\
MILE 2 & 3 & 1.0 \\
OSHODI & 22 & 12.0 \\
SHOGUNLE & 8 & 4.0 \\
SURULERE & 15 & 8.0 \\
YABA & 30 & 17.0 \\
Total & 174 & 100.0 \\
\hline
\end{tabular}

Foods in bukas sampled were prepared mostly by both the owners and hired workers $(51.7 \%)$. In other cases, foods were prepared by only the owners $(26.7 \%)$ and the hired workers $(21.7 \%)$.

The owners who washed hands always before preparing food were $54.3 \%$ while $27.7 \%$ did not always wash their hands. Before preparing food $42.0 \%$ of the hired workers washed hands always; $39.8 \%$ washed sometimes while $18.2 \%$ did not wash their hands.

Majority of the respondents (77.7\%) were located in markets with toilet facilities while $22.3 \%$ did not have toilet facilities in their markets. After using toilets, $71.8 \%$ washed their hands with soap and water while $28.2 \%$ washed their hands with only water. The sources of water used for washing hands were public tap (54.7\%) and water storage container $(35.8 \%)$. Other sources included 'pure water' $(7.4 \%)$, water brought from home $(2.2 \%)$.

\subsection{Symptoms Felt by Respondents during Episodes of Typhoid Fever}

From the questionnaire, $69.4 \%$ of the respondents reported headache, diarrhea $(4.1 \%)$, abdominal cramps (30.6\%), fever $(26.5 \%)$, vomiting $(2.0 \%)$, weakness $(34.7 \%)$, dizziness $(26.5 \%)$, tiredness $(40.8 \%)$, and loss of appetite (20.4\%) as what they experienced during episodes of typhoid fever.

\subsection{Type of Apartment}

More than half of the respondents lived in a one-room apartment, $67.3 \%$, while the rest lived in self-contained flat $(16.3 \%)$ and other types of accommodation (16.3\%). The average number of persons living in the different types of apartments was $4.1 \pm 1.9,4.1 \pm 1.8$ and $6.3 \pm$ 
1.8 for one-room, self-contained and other types of accommodation respectively.

\subsection{Respondent's Knowledge of the Disease}

Ninety percent $(90 \%)$ of the respondents have heard of typhoid fever while $10 \%$ have not heard. On how the disease was contracted, $38.9 \%$ said contaminated water, $23.8 \%$ contaminated food, $4.3 \%$ not washing hands. Other responses were dirty environment $8.6 \%$; too much work/stress $7.0 \%$, walking in the sun $2.7 \%$; while $5.9 \%$ did not know.

Thirty-eight point two percent (38.2\%) said they had suffered from typhoid fever while $61.0 \%$ had not; $0.8 \%$ were not sure if they had had typhoid. However, majority of the respondents $(50.8 \%)$ said they had household members who had suffered from typhoid, 33.3\% did not have, while $15.8 \%$ did not know if any member of their household had had typhoid.

\subsection{Sources of Information}

On how they knew the fever was typhoid, 38.5\% said they went for a blood test, $37.6 \%$ was told by a doctor, and $13.7 \%$ was told by a nurse. Only $3.4 \%$ went for stool test, $3.4 \%$ knew from past experience, and $2.6 \%$ knew through other ways.

Majority of the typhoid fever were treated in a hospital $60.0 \%$. Others were treated in a chemist $23.5 \%$; "agbo" (a local herb concoction) was used in $15.3 \%$ of cases while $1.2 \%$ did nothing.

\subsection{Prior Treatment Sources}

Twenty respondents (11\%) had had previous antibiotic treatment before being diagnosed as having typhoid fever. The drugs used were ampicillin $6(30.0 \%)$, amoxil $5(25.0 \%)$, chloramphenicol 3(15.0\%), ampiclox $3(15.0 \%)$. Tetracycline, ampicillin and fulcin were used by $5 \%$ of these respondents respectively.

The respondents sought for treatment from doctors $17(85 \%)$, Nurses $4(20.0 \%)$ and self treated $8(40.0 \%)$. Thus some sought treatment from more than one source.

Where investigated, the diagnosis was based on laboratory result (60.0\%) and clinical presentation (40.0\%).

Self treated means they were able to access antibiotics and other forms of treatment without a doctor's prescription.

\section{DISCUSSION}

From this study, $27.7 \%$ of owners wash hands sometimes before preparing food, while $18.2 \%$ of the hired workers do not wash their hands at all. This is alarming because one of the main sources of pathogen transfer such as Salmonella spp is through improper hand wash- ing. Since pathogens of faecal, nose or throat and skin origin are most likely to be transmitted by the hands, there is need for the food handlers to be informed about the importance for effective hand hygiene and other barriers to pathogen contamination. In another Nigerian study by Okojie et al. [8], on the assessment of hygiene among food handlers in a Nigerian University, there was a very low frequency of hand hygiene and a poor knowledge and practise of food hygiene amongst the food handlers. A report by Mohan et al. [13] on the carrier state of S. Typhi and intestinal parasites and personal hygiene, showed that $0.47 \%$ of the food handlers studied harboured S. Typhi and it was attributable to their poor personal hygiene.

Non-typhoidal Salmonella was isolated from the stool of $10 \%$ of asymptomatic food workers in Thailand [14]. In the US, Buchwald and Blaser [15] estimated that 200,000 individuals may be excreting non-typhi Salmonella at any one time and many of these excretors would be food workers.

During food production and preparation, since both healthy and infected workers stay at work for several days, the possibility therefore exists for healthy individuals to be continually exposed to these infected workers [4].

These infected workers could be in the aymptomatic stage and still harbour millions of infectious organisms in their stools without any sympton of infection. To prevent pathogen transmission therefore one needs to adhere strictly to effective hand washing barrier creation to prevent such pathogens from being transmitted to foods [4].

In a study from Japan on Salmonella carriage rate amongst food workers, 331,644 faecal specimens were collected from workers in hotels, supermarket, food factories, and restaurants; only $0.032 \%$ of the faecal samples harboured Salmonella, and the most common serovars were Agona, Corvallis, Infantis and Enteritidis [16].

A report in Nigeria by Smith et al. [9] showed that $5.7 \%$ of the food handlers harboured S. Typhi. However from a report from Ethiopia by Andargie et al. [5] Salmonella spp was not isolated from the food handlers working in a caferteria in the University.

From this study, $28.2 \%$ of food handlers wash their hands with water only after using the toilet. This also implies improper hand-washing and the possibility of Salmonella transmission to the foods prepared or eaten by the food handlers. The importance of hand washing with soap cannot be overemphasized; as a report by Fewtrell et al. [17] suggested that intensive hygiene education that includes promoting hand washing with soap, proper dirt and faecal disposal, disallowing open 
de-faecation by children, has been shown to reduce diarrhoeal disease incidence in young children.

This highlights the risks that occur in food preparation venues where there are opportunities for faecal and nasal contamination of hands on a regular basis and a lack of adequate hand washing.

It has been reported that three percent of typhoid fever survivors become permanent carriers, with the organism present in the gallbladder, biliary tract, or rarely the intestine or urinary tract [18].

The authors concluded that asymptomatic Salmonella excretors have a low risk of transferring Salmonella from their stools by their hands to food and suggested hand contamination with Salmonella to more likely be due to inconsistent hand washing during preparation of meat [19].

Salmonella Typhi and Salmonella Paratyphi also can be detected in urine during systemic infection [20], emphasizing the importance of effective hand hygiene even for food workers who use the toilet only for urination.

The majority of the food worker-associated outbreaks reviewed by Greig et al. [2] and Todd et al. [22-23] involved transmission of the pathogen to food by food handlers' hands. In fact hand contact was described as a factor in $40 \%$ of the 816 outbreaks, and the investigators specifically mentioned that the food handlers were not wearing gloves in $1.3 \%$ of the outbreaks. The authors further stated that bare hand contact may have contributed to more outbreaks if gloves had not been worn regularly, but data on wearing of gloves were not recorded during their investigations. In our own study there was no data on wearing of gloves. Investigators [22-23] also noted that provision of sinks and toilet facilities with adequate water supplies were lacking in such studies. These Researchers also identified street vendors as the source of faecally contaminated foods, particularly in developing countries. Toilets, toilet paper, and clean water for hand washing often are not readily available, which is a phenomen that is also true for the typical Nigerian buka.

A study conducted by Senthilkumar and Prabakaran [12] showed that the food handlers played prominent role in transmission of typhoid bacilli through different food products and water and the carrier state of typhoid was observed in the age group 15-45 years. Another study carried out by Sur et al. [24] showed that Residents in areas with a high risk for typhoid fever were made of those with lower education levels and economic status, bigger families, and lived close to areas where there are rivers and streams. Our study did not however look into the literacy rate but the food handlers sampled had bigger families and low economic status.
Although 90\% had heard about typhoid fever, 15.6\% did not know how it is contracted. In addition, when asked how they knew the fever they had was caused by typhoid fever only 3.4\% said they went for a stool test. Eighty point five percent $(80.5 \%)$ of the food handlers had primary education and this could probably account for the poor hygiene practise amongst the food handlers. It is interesting to note that although some had no formal education some of them had heard about typhoid fever. Another report by Andargie et al. [5] suggested from their study that the reason for infection amongst the food handlers surveyed was due to their low education level $(6.3 \%)$. In contrast, the study by Zain and Naing [25], reported that although the food handlers surveyed with no formal education accounted for $10.5 \%$ there was no significant difference in the attitudes and practice between trained and untrained food handlers.

There is, however a potential source of bias in this study since the convenient sampling method was used and large number of food handlers in a particular region were not interviewed.

\section{CONCLUSIONS}

It is recommended for public health policy and practice that in order to reduce transmission of typhoid fever and other communicable diseases among food handlers, hand washing, universal use of plastic gloves and proper waste disposal system should be mandatory. In addition, there should be access to clean water and sanitary toilets near food service areas.

The Government (both State and Federal) should also embark on enlightenment campaigns on a regular basis and health hygiene training and retraining sessions should be undertaken for these food handlers to create awareness about the importance of health hygiene and the risks asociated with non compliance with the rules and regulations that govern food handlers.

\section{ACKNOWLEDGEMENTS}

Source of funding: International Foundation for Science (IFS) grant no: E/4020-1 to SIS.

\section{REFERENCES}

[1] Thong, K.L., Cheong, Y.M., Puthucheary, S., et al. (1994) Epidemiologic analysis of Salmonella typhi isolates and those from outbreaks by pulsed-field gel electrophoresis. Journal of Clinical Microbiology, 32(5),1135-1141.

[2] Todd, E.C.D., Greig, J.D., Bertleson, C.A., et al. (2008a) Outbreaks where food workers have been implicated in the spread of food borne disease. Part 4. Infective doses and pathogen carriage. Journal of Food Protection, 71(11), 
2339-2373.

[3] Todd, E.C.D., Greig, J.D., Bertleson, C.A., et al. (2008b) Outbreaks where food workers have ben implicated in the spread of food borne disease. Part 5. Sources of contamination and pathogen excretion from infected persons. Journal of Food Protection, 71(12), 2582-2595.

[4] Todd, E.C.D., Greig, J.D., Bertleson, C.A., et al. (2009) Outbreaks where food workers have been implicated in the spread of food borne disease. Part 6. Transmission and survival of pathogens in food processing and preparation environment. Journal of Food Protection, 72(1), 202-219.

[5] Andargie, G., Kassu, A., Moges, F., Tiruneh, M. and Huruy, K. (2008) Prevalence of bacteria and intestinal parasites among food handlers in Gondar Town, Northwest Ethiopia. Journal of Health Population and Nutrition, 26(4), 451-455.

[6] Malhotra, R., Lai, P., Krishna, P.S., Daga, M.K. and Kishore, J. (2008) Evaluation of health education intervention on knowledge and attitude of food handlers working in a medical college in delhi, India. Asia Pacific Journal of Public Health, 20(4), 277-286.

[7] van Tonder, I., Lues, J.F. and Theron, M.M. (2007) The personal and general hygiene practices of food handlers in the delicatessen sections of retail outlets in South Africa. Journal of Environmental Health, 70(4), 33-38.

[8] Okojie, O.H., Wagbatsoma, V.A. and Ighoroge, A.D. (2005) An assessment of food hygiene among food handlers in a Nigerian University campus. Nigerian Postgraduate Medical Journal, 12(2), 93-96.

[9] Smith, S.I., Alao, F., Goodluck, H.T., et al. (2008) Prevalence of Salmonella typhi among food handlers from bukkas in Nigeria. British Journal of Biomedical Sciences, 65(3), 158-160.

[10] Smith, S.I., Bamidele, M., Goodluck, H.A., et al. (2009) Antimicrobial susceptibilities of Salmonella isolated from food handlers and cattle in Lagos, Nigeria. International Journal of Health Research, 2(2), 189-193.

[11] Smith, S.I., Odunukwe, N.N., Niemogha, M-T, et al. (2004) Diagnostic methods for typhoid fever in Nigeria. British Journal of Biomedical Sciences, 61(4), 179-181.

[12] Senthilkumar, B. and Prabakaran, G. (2005) Multi drug resistant Salmonella Typhi in asymptomatic typhoid carriers among food handlers in Nammakal District, Tamil Nadu. Indian Journal of Medical Microbiology, 23(2), 92-94.

[13] Mohan, U., Mohan, V. and Raj, K.A. (2006) Study of Carrier State of S. Typhi, Intestinal Parasites \& Personal Hygiene amongst Food Handlers in Amritsar City. Indian Journal of Community Medicine, 31, 60-61.

[14] Sirinavin, S., Thavornnunth, J., Sakchainanont, B., et al. (2003) Norfloxacin and azithromycin for treatment of nontyphoidal Salmonella carriers. Clinical Infectious
Diseases, 37(5), 685-691.

[15] Buchwald, D.S. and Blaser, M.J. (1984) A review of human salmonellosis. II. Duration of excretion following infection with nontyphi Salmonella. Review of Infectious Diseases, 6(3), 345-356.

[16] Murakami, K., Ishihara, T., Horikawa, K. and Oda, T. (2007) Features of Salmonella serovars among food handlers in Kyushu, Japan. New Microbiology, 30(2), 155-159.

[17] Fewtrell, L., Kaufmann, R.B., Kay, D., Enanoria, W., Haller, L. and Colford, J.M. (2005) Water, sanitation and hygiene interventions to reduce diarrhea in less developed countries; a systematic review and meta-analysis. Lancet Infectious Diseases, 5(1), 42-52.

[18] Brooks, G.F. and Carroll, K.C. (2004) Enteric gramnegative rods (Enterobacteriaceae), chap. 16. In: Brooks, G.F., Carroll, K.C., Butel, J.S. and Morse, S.A., Eds., Jawetz, Melnick \& Adelberg's medical microbiology, 24th Edition.

[19] Kohl, K.S., Rietberg, K., Wilson, S. and Farley, T.A. (2002) Relationship between home food-handling practices and sporadic salmonellosis in adults in Louisiana, United States. Epidemiology and Infection, 129(2), 267-276.

[20] Braddick, M.R., Crump, B.J. and Yee, M.L. (1991) How long should patients with Salmonella typhi or Salmonella paratyphi be followed-up? A comparison of published guidelines. Journal of Public Health Medicine, 13(2), 101-107.

[21] Greig, J.D., Todd, E.C.D., Bartleson, C. and Michaels, A. B. (2007) Outbreaks where food workers have been implicated in the spread of foodborne disease. Part 1. Description of the problem, methods and agents involved. Journal of Food Protection, 70(7), 1752-1761.

[22] Todd, E.C.D., Greig, J.D. and Bartleson, C.A., et al. (2007a) Outbreaks where food workers have been implicated in the spread of foodborne disease. Part 2. Description of outbreaks by size, severity, and settings. Journal of Food Protection, 70(8), 1975-1993.

[23] Todd, E.C.D., Greig, J.D. and Bartleson, C.A., et al. (2007b) Outbreaks where food workers have been implicated in the spread of foodborne disease. Part 3. Factors contributing to outbreaks and description of outbreak categories. Journal of Food Protection, 70(9), 2199-2217.

[24] Sur, D., Ali, M., von Seidlein, L., et al. (2007) Comparisons of predictors for typhoid and paratyphoid fever in Kolkata, India. BMC Public Health, 7, 289-298.

[25] Zain, M.M. and Naing, N.N. (2002) Sociodemographic characteristics of food handlers and their knowledge, attitude and practice towards food sanitation: A preliminary report. Southeast Asian Journal of Tropical Medicine and Public Health, 33(2), 410-417. 